\title{
Quantity Competition and Price Competition with a Duopoly in a Consumer-Friendly Firm: A Welfare Analysis
}

\author{
Yasuhiko Nakamura \\ College of Economics, Nihon University, Tokyo, Japan \\ Email: yasuhiko.r.nakamura@gmail.com
}

Received September 18, 2013; revised October 15, 2013; accepted October 20, 2013

Copyright (C) 2013 Yasuhiko Nakamura. This is an open access article distributed under the Creative Commons Attribution License, which permits unrestricted use, distribution, and reproduction in any medium, provided the original work is properly cited.

\begin{abstract}
This paper conducts a welfare analysis in a duopoly with differentiated and substitutable goods composed of one consumer-friendly firm and one absolute profit maximizing firm. We suppose that the consumer-friendly firm maximizes the weighted sum of its absolute profit and consumer surplus. In such a duopoly, when the degree of product differentiation is sufficiently high and the weight that the consumer-friendly firm puts on consumer surplus in its objective function is sufficiently high, the equilibrium social welfare is larger in the quantity competition than in the price competition, which implies that the result is reverse of that obtained in the standard duopoly with substitutable goods composed of absolute profit maximizing firms.
\end{abstract}

Keywords: Consumer-Friendly Firm; Degree of Product Differentiation; Extent of Importance of Consumer Surplus

\section{Introduction}

This paper compares the equilibrium market outcomes between the quantity competition and the price competition in a duopoly with differentiated and substitutable goods composed of one consumer-friendly firm and one absolute profit-maximizing firm. In this paper, we assume that the consumer-friendly firm maximizes the weighted sum of its absolute profit and consumer surplus. The purpose of this paper is to find whether or not there exists a condition on the degree of product differentiation and the extent of the importance that the consumerfriendly firm places on consumer surplus such that the ranking order of the equilibrium social welfare between the quantity competition and the price competition becomes the reverse of that obtained in the standard duopoly with substitutable goods composed of absolute profit-maximizing firms.

In the modern real world economy, the importance of corporate social responsibility (CSR), which includes social and environmental issues is increasing; such CSR activity often receives broad coverage in journals and in

${ }^{*}$ We are grateful for the financial support of KAKENHI (25870113). All remaining errors are our own. public media. Reflecting this trend, many firms' investors and consumers focus on what degree of CSR activity to carries out. Specifically, many consumers are willing to pay a higher price for products with CSR attributes ${ }^{1}$. In addition, many empirical studies have considered the link between corporate social performance (CSP) and corporate financial performance (CFP). McWilliams et al. [3] first proposed an agenda to explore such a relation between CSP and CFP; subsequently, Brammer and Millington [4] explored corporate charitable giving as an aspect of the relationship between CSP and CFP within the context of a specific component of $\mathrm{CSP}^{2}$.

The interaction between the firms' governance on CSR and product market competition is also interesting, and its welfare implications are worthy of studying the welfare. The economic literature on CSR is relatively recent. Kopel and Brand [9] analyzed a quantity-setting duopoly consisting of a consumer-friendly firm and an absolute profit maximizing firm and showed that the owners of both firms endogenously hire their managers and dele-

\footnotetext{
${ }^{1}$ Recent empirical evidence is provided in Auger et al. [1] and Trudel and Cotte [2].

${ }^{2}$ Similarly, empirical works that show a positive relation between CSP and CFP include Carroll and Shabana [5], Godfrey et al. [6], Hillman and Keim [7], and Surroca et al. [8].
} 
gate their production choices in the equilibrium ${ }^{3}$. Following Kopel and Brand [9] and Lambertini and Tampieri [11], this paper considers the equilibrium market outcomes including social welfare, by focusing on the interrelation between firms' governance on CSR and product market competition. Although the existing works in this area such as Kopel and Brand [9] and Lambertini and Tampieri [11] fixed a type of market competition. In this paper, we attempt to derive a new welfare implication by comparing the equilibrium social welfare from the viewpoints of the quantity competition and the price competition.

In this paper, we show that the equilibrium social welfare can be larger in the quantity competition than in the price competition, even in the duopoly with differentiated and substitutable goods, when the degree of production differentiation is sufficiently high and the extent of the importance of consumer surplus to the consumerfriendly firm is relatively high ${ }^{4}$. The intuition behind this result is given by the effect of the extent of the importance of consumer surplus to the consumer-friendly firm on the strategic relation of the strategic variables between the two firms in both the quantity competition and the price competition in addition to the effect of the degree of product differentiation on the intensity of market competition. More precisely, first, when the degree of product differentiation is sufficiently high, since the market competition is less intense, the difference in the equilibrium social welfare between the quantity competition and the price competition becomes relatively small. Moreover, as the extent of the importance of consumer surplus to the consumer-friendly firm increases, both the strategic substitutability of the output levels between the two firms in the quantity competition and the strategic complementarity of the price levels between the two firms in the price competition become sufficiently weak. This effect of the extent of the importance of consumer surplus to the consumer-friendly firm on the strategic relation between the strategic variables of the two firms reverses the ranking order of the equilibrium consumer surplus between the quantity competition and the price competition, which implies that the equilibrium social welfare is larger in the quantity competition than in the price competition even in the duopoly with substitutable goods. This result contrasts strikingly with that obtained

\footnotetext{
${ }^{3}$ As another strand in this field, Besley and Ghatak [10] identified CSR activity with the creation of public goods or the curtailment of public bads. In addition, Lambertini and Tampieri [11] investigated how CSR firms influence a Cournot oligopoly with pollution.

${ }^{4}$ In the model with product differentiation in the fashion of Singh and Vives [12] which is employed in this paper, as parameter $b$ which indicates the degree of product differentiation becomes higher (lower), we note that the relation between the goods produced by the con- sumer-friendly firm and the absolute profit maximizing firm is more homogeneous (independent).
}

in the standard duopoly with substitutable goods composed of absolute profit-maximizing firms only. The main message from this result is that an increase in the importance of CSR behavior in the modern real world economy may reverse the welfare implications obtained in the standard duopoly. In particular, policy makers must pay attention to changing welfare implications in the modern real world economy such that the CSR conducted by each firm drastically increases.

The remainder of this paper is organized as follows. In Section 2, we formulate the quantity-setting and pricesetting duopolistic model with differentiated and substitutable goods composed of one consumer-friendly firm and one absolute profit maximizing firm that will be investigated in this paper. In Section 3, we derive the equilibrium market outcomes both in the quantity competition and in the price competition, and we compare the equilibrium social welfare in the quantity competition with that in the price competition. Section 4 concludes with several remarks. The concrete value of the difference in the equilibrium social welfare between the quantity competition and the price competition is given in the Appendix.

\section{Model}

We formulate a quantity-setting and price-setting mixed duopolistic model with differentiated and substitutable goods composed of one consumer-friendly private firm (firm 0) which maximizes the weighted sum of its absolute profit and consumer surplus and one private firm (firm 1) which maximizes its absolute profit. The basic structure of the model follows a standard product differentiation model as in Singh and Vives [12]. Thus, firms 0 and 1 face the following inverse demand function:

$p_{i}=a-q_{i}-b q_{j}$, where $q_{i}$ is the quantity of good $i$ and $p_{i}$ is its price $(i, j=0,1 ; i \neq j)$. Note that $a>0$ and $b \in(0,1)$ are demand parameters, with $b$ denoting the degree of product differentiation. This inverse demand system can be described with a quasi-linear representative consumer utility function of the form

$$
U\left(q_{0}, q_{1} ; q\right)=a\left(q_{0}+q_{1}\right)-\frac{q_{0}^{2}+2 b q_{0} q_{1}+q_{1}^{2}}{2}+q,
$$

where $q$ represents the numeraire goods. Let $\pi_{i}$ be firm $i$ 's profit, which is equal to $\pi_{i}=\left[p_{i}-C_{i}\left(q_{i}\right)\right] q_{i}$, $(i=0,1)$. Let firm $i$ 's production cost function be $C_{i}\left(q_{i}\right)=f_{i}+c_{i} q_{i}$, where $f_{i}$ is a fixed cost and $c_{i}$ is a constant marginal cost, $(i=0,1)$. For simplicity, we assume that $f_{1}=f_{2}=0$ and $c_{0}=c_{1}=0$ with no loss of generality since we do not consider the free entry problem and we focus on the degree to which firm 0 emphasizes consumer surplus in its objective function.

Then, following Goering [13], Goering [14], Goering [15], and Kopel and Brand [9] it is assumed that the ob- 
jective functions of Firms 0 and 1 are given as follows:

$$
V_{0}=\pi_{0}+\theta C S, \quad V_{1}=\pi_{1},
$$

where $\theta \in\left[0,(2-b) /\left(2-b^{2}\right)\right)$ denotes the parameter that firm 0 puts on consumer surplus in its objective function ${ }^{5}$. As usual, $W$ is the total social surplus (the sum of consumer surplus and the profits of firms 0 and $1)$.

Under the above setting, in the next section, we will derive the equilibrium market outcomes both in the quantity competition and in the price competition.

\section{Equilibrium Analysis}

\subsection{Quantity Competition}

In this subsection, we discuss the quantity competition where firms 0 and 1 simultaneously choose their output levels. The weighted sum of the absolute profit of firm 0 and consumer surplus, which is its objective function, $V_{0}\left(q_{0}, q_{1} ; \theta\right)$, is given as follows:

$$
V_{0}\left(q_{0}, q_{1} ; \theta\right)=\left(a-q_{0}-b q_{1}\right) q_{0}+\theta\left(q_{0}^{2}+2 b q_{0} q_{1}+q_{1}^{2}\right) / 2 \text {. }
$$

On the other hand, the absolute profit of Firm 1, which is its objective function, $V_{1}\left(q_{0}, q_{1}\right)$, is given as follows:

$$
V_{1}\left(q_{0}, q_{1}\right)=\left(a-q_{1}-b q_{0}\right) q_{1} .
$$

The respective reaction functions of Firms 0 and 1 , $R_{0}\left(q_{1} ; \theta\right)$ and $R_{1}\left(q_{0}\right)$, are given as follows:

$$
\left\{\begin{array}{l}
q_{0}=R_{0}\left(q_{1} ; \theta\right)=\left[a-b q_{1}(1-\theta)\right] /(2-\theta), \\
q_{1}=R_{1}\left(q_{0}\right)=\left(a-b q_{0}\right) / 2
\end{array}\right.
$$

yielding

$$
\begin{gathered}
q_{0}^{q q}=\frac{a[2-b(1-\theta)]}{4-b^{2}(1-\theta)-2 \theta}, \quad q_{1}^{q q}=\frac{a(2-b-\theta)}{4-b^{2}(1-\theta)-2 \theta}, \\
p_{0}^{q q}=\frac{a\left(2-b-2 \theta+b^{2} \theta\right)}{4-b^{2}(1-\theta)-2 \theta}, \quad p_{1}^{q q}=\frac{a(2-b-\theta)}{4-b^{2}(1-\theta)-2 \theta}, \\
\pi_{0}^{q q}=\frac{a^{2}[2-b(1-\theta)]\left(2-b-2 \theta+b^{2} \theta\right)}{\left[4-b^{2}(1-\theta)-2 \theta\right]^{2}}, \\
\pi_{1}^{q q}=\frac{a^{2}(2-b-\theta)^{2}}{\left[4-b^{2}(1-\theta)-2 \theta\right]^{2}},
\end{gathered}
$$

$$
\begin{gathered}
C S^{q q}=\frac{a^{2}(1+b)\left[8+2 b^{2}(1-\theta)-4 \theta+\theta^{2}-b\left(8-6 \theta+\theta^{2}\right)\right]}{2\left[4-b^{2}(1-\theta)-2 \theta\right]^{2}}+q, \\
W^{q q}=\frac{a^{2}\left[24-2 b^{3}(1-\theta)^{2}-20 \theta+3 \theta^{2}-b^{2}\left(2-6 \theta+\theta^{2}\right)-2 b\left(8-7 \theta+2 \theta^{2}\right)\right]}{2\left[4-b^{2}(1-\theta)-2 \theta\right]^{2}}+q .
\end{gathered}
$$

Note that all the above results are given under the condition that $\theta<(2-b) /\left(2-b^{2}\right)$.

\subsection{Price Competition}

In this subsection, we discuss the quantity competition where firms 0 and 1 simultaneously choose their output levels. The weighted sum of the absolute profit of firm 0 and consumer surplus, which is its objective function, $V_{0}\left(q_{0}, q_{1} ; q\right)$, is given as follows:

$$
V_{0}\left(p_{0}, p_{1} ; \theta\right)=\frac{\left[a(1-b)-p_{0}+b p_{1}\right] p_{0}}{1-b^{2}}+\theta\left[\frac{2 a^{2}(1-b)+p_{0}^{2}-2 b p_{0} p_{1}+p_{1}^{2}-2 a(1-b)\left(p_{0}+p_{1}\right)}{2\left(1-b^{2}\right)}\right]
$$

On the other hand, the absolute profit of firm 1 which is its objective function, $V_{1}\left(p_{0}, p_{1}\right)$, is given as follows:

$$
V_{1}\left(p_{0}, p_{1}\right)=\frac{\left[a(1-b)+b p_{0}-p_{1}\right] p_{1}}{1-b^{2}} .
$$

The respective reaction functions of firms 0 and 1 , $R_{0}\left(p_{1} ; \theta\right)$ and $R_{1}\left(p_{0}\right)$, are given as follows:

$$
\left\{\begin{array}{l}
p_{0}=R_{0}\left(p_{1} ; \theta\right)=\left[a(1-b)+b p_{1}\right](1-\theta) /(2-\theta), \\
p_{1}=R_{1}\left(p_{0}\right)=\left[a(1-b)+b p_{0}\right] / 2
\end{array}\right.
$$

\footnotetext{
${ }^{5}$ Although it is natural that the domain of $\theta$ is a closed interval $[0,1]$, the absolute profit of firm 0 can be negative through the negative price level of firm 0 since the market competition is too intense in the quantity-setting duopoly when parameter $\theta$ is high relative to the value of $b$, that is, $\theta \geq(2-b) /\left(2-b^{2}\right)$. Therefore, we omit interval $\left[(2-b) /\left(2-b^{2}\right), 1\right]$ as the effective domain of $\theta$.
} 
yielding

$$
\begin{gathered}
q_{0}^{p p}=\frac{a(2+b)}{(1+b)\left[4-b^{2}(1-\theta)-2 \theta\right]}, \quad q_{1}^{p p}=\frac{a(2+b-\theta-b \theta)}{(1+b)\left[4-b^{2}(1-\theta)-2 \theta\right]}, \\
p_{0}^{p p}=\frac{a(1-b)(2+b)(1-\theta)}{4-b^{2}(1-\theta)-2 \theta}, \quad p_{1}^{p p}=\frac{a(1-b)[2+b(1-\theta)-\theta]}{4-b^{2}(1-\theta)-2 \theta}, \\
\pi_{0}^{p p}=\frac{a^{2}(1-b)(2+b)^{2}(1-\theta)}{(1+b)\left[4-b^{2}(1-\theta)-2 \theta\right]^{2}}, \quad \pi_{1}^{p p}=\frac{a^{2}(1-b)[2+b(1-\theta)-\theta]^{2}}{(1+b)\left[4-b^{2}(1-\theta)-2 \theta\right]^{2}}, \\
W^{p p}=\frac{a^{2}\left[24+2 b^{3}(1-\theta)^{2}-20 \theta+3 \theta^{2}-b^{2}\left(2-6 \theta+\theta^{2}\right)-2 b\left(8-7 \theta+2 \theta^{2}\right)\right]}{2\left[4-b^{2}(1-\theta)-2 \theta\right]^{2}}+q .
\end{gathered}
$$

Comparing the equilibrium social welfare between the quantity competition and the price competition, we obtain the following result:

$$
\left\{\begin{array}{l}
W^{q q}>W^{p p}, \text { if. } \frac{2+4 b-2 b^{2}-2 b^{3}-A \sqrt{2}}{4+3 b-3 b^{2}-2 b^{3}}<\theta<\frac{2+4 b-2 b^{2}-2 b^{3}+A \sqrt{2}}{4+3 b-3 b^{2}-2 b^{3}}, \\
W^{p p}>W^{q q}, \text { otherwise. }
\end{array}\right.
$$

where $A=\sqrt{2-8 b+10 b^{3}-b^{4}-3 b^{5}}$.

The above result on the ranking order of the equilibrium social welfare between the quantity competition and the price competition leads to the following:

Proposition 1 In a duopoly with differentiated and substitutable goods which is composed of consumer-friendly firm 0 and absolute profit maximizing firm 1, the equilibrium social welfare can be larger in the quantity competition than in the price competition when the degree of product differentiation, $b$, is sufficiently low and the extent of the importance of consumer surplus to consumerfriendly firm 0 is relatively high.

The result stated in Proposition 1 can be the reverse of that obtained in the standard duopoly with substitutable goods composed of absolute profit maximizing firms only. In the standard duopoly with substitutable goods, it is well known that the social welfare is always larger in the price competition than in the quantity competition since the market competition is relatively intense owing to the strategic complementarity of the price levels between the consumer-friendly firm 0 and the absolute profit-maximizing firm 1 .

In Figure 1, the difference in the equilibrium social welfare between the price-setting competition and the quantity competition is described. The intuition behind

${ }^{6}$ We provide the concrete difference between $W^{q q}$ and $W^{p p}$ in the Appendix.

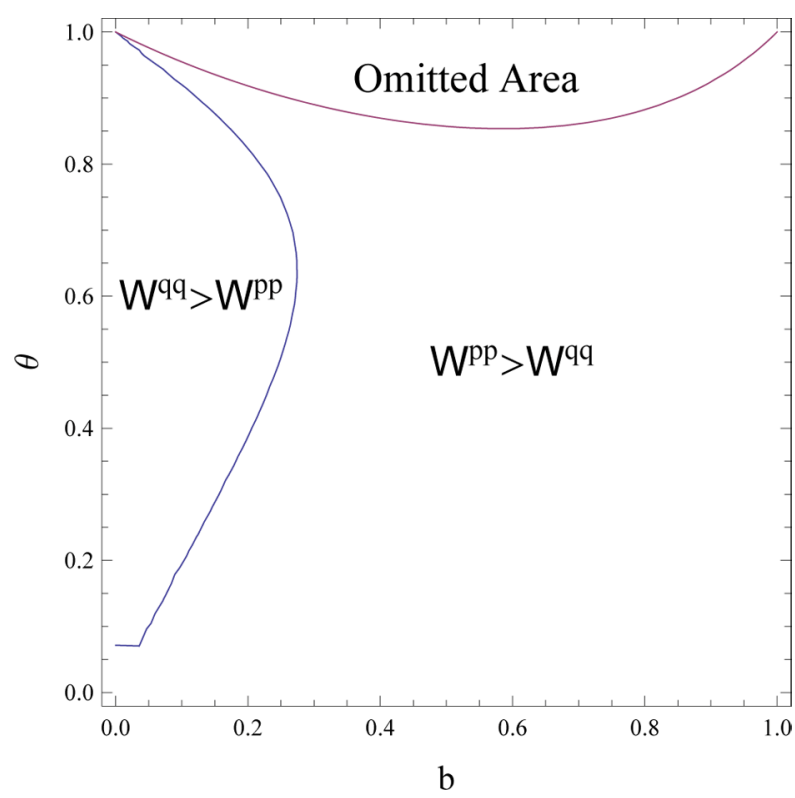

Figure 1. Difference in the equilibrium social welfare between the quantity competition and the price competition.

this result is as follows. First, when the value of $b$ is sufficiently low, the difference in the social welfare between the quantity competition and the price competition tends to be low, since the relation of the goods produced by firms 0 and 1 is nearly independent. Second, as $\theta$ increases, both the strategic substitutability of the output 
levels between firms 0 and 1 in the quantity competition and the strategic complementarity of the price levels between firms 0 and 1 in the price competition are sufficiently weak ${ }^{7}$. Thus, the output level of firm 0 is larger in the quantity competition than in the price competition when the extent of the importance of consumer surplus to firm $0, \theta$, is high relative to the degree of product differentiation, $b^{8}$. Hence, the consumer surplus is larger in the quantity competition than in the price competition, particularly when the degree of product differentiation, $b$, is sufficiently low and the extent of the importance of consumer surplus to firm $0, \theta$, is relatively high. Therefore, with the above two effects of $b$ and $\theta$, the equilibrium social welfare becomes larger in the quantity competition than in the price competition owing to the reverse ranking of the equilibrium consumer surplus between the quantity competition and the price competition when the degree of product differentiation, $b$, is sufficiently low and the extent of the importance of consumer surplus to firm $0, \theta$, is relatively high.

Therefore, the statement in Proposition 1 indicates that if the consumer-friendly firm implements more CSR activity more strictly, thus reflecting the mode in the modern real world economy where strong CSR activity is desired, the welfare implication is against the commonly known convention obtained in the standard oligopolistic theory.

\section{Conclusions}

This paper compared the equilibrium social welfare between the quantity competition and the price competition in a duopoly with differentiated and substitutable goods composed of one consumer-friendly firm and one absolute profit maximizing firm. In this paper, we supposed that the consumer-friendly firm maximizes the weighted sum of its absolute profit and consumer surplus. In such a duopoly, we derived the conditions of both the degree of product differentiation and the extent of importance on

${ }^{7}$ More precisely, from easy calculations, we obtain the following results:

$$
\left\{\begin{array}{c}
\partial R_{0}\left(q_{1} ; \theta\right) / \partial q_{1}=-b(1-\theta) /(2-\theta) \\
\quad \text { and } \partial^{2} R_{0}\left(q_{1} ; \theta\right) / \partial \theta \partial q_{1}=b /(2-\theta)^{2}>0, \\
\partial R_{0}\left(p_{1} ; \theta\right) / \partial p_{1}=b(1-\theta) /(2-\theta) \\
\quad \text { and } \partial^{2} R_{0}\left(p_{1} ; \theta\right) / \partial \theta \partial p_{1}=-b /(2-\theta)^{2}<0 .
\end{array}\right.
$$

Thus, in the quantity competition, as the value of $\theta$ increases, we find that the strategic substitutability of the output level of Firm 0 to that of Firm 1 becomes weaker, whereas the strategic complementarity of the price level of Firm 0 to that of Firm 1 becomes weaker.

${ }^{8}$ More concretely, we find that

$$
\begin{aligned}
& q_{0}^{p p}-q_{0}^{q q} \\
& =a b[b(1-\theta)-\theta] /(1+b)\left[4-b^{2}(1-\theta)-2 \theta\right] \gtreqless 0 . \\
& \Leftarrow \theta \lesseqgtr b /(1+b)
\end{aligned}
$$

consumer surplus of the consumer-friendly firm and found that the equilibrium social welfare can be larger in the quantity competition than in the price competition, which is strikingly different from the result obtained in the standard duopoly with substitutable goods composed of absolute profit-maximizing firms only.

In this paper, we found that when the value of the parameter that represents the degree of product differentiation of the goods produced by the consumer-friendly firm and the absolute profit-maximizing firm is sufficiently low and the extent of the importance of consumer surplus to the consumer-friendly firm is relatively high, the equilibrium social welfare in the duopoly wherein the consumer-friendly firm and the absolute profit maximizing firm coexist can be larger in the quantity competition than in the price competition. The intuition behind this result is given by the effect of the extent of the importance of consumer surplus to the consumer-friendly firm on the strategic relation of strategic variables between the two firms in addition to that of the degree of product differentiation. When the product differentiation of the goods produced by the two firms is sufficiently high, the market competition is less intense, and the difference in the equilibrium social welfare between the quantity competition and the price competition tends to be low. Moreover, as the extent of the importance of consumer surplus to the consumer-friendly firm increases, both the strategic substitutability of the output levels between the two firms in the quantity competition and the strategic complementarity of the price levels between the two firms are sufficiently weak; consequently, the output level of the consumer-friendly firm becomes larger in the quantity competition than in the price competition. Thus, in such a case, since the equilibrium consumer surplus is larger in the quantity competition than in the price competition, the equilibrium social welfare can be larger in the quantity competition than in the price competition in the duopoly with substitutable goods. Therefore, in the modern real world economy, in which firms must show greater corporate social responsibility (CSR), policy makers must note that the welfare implication should be the reverse of that obtained in the standard duopoly with substitutable goods composed of absolute profit maximizing firms.

Finally, we mention an issue to be addressed in the future. Throughout this paper, we assumed the symmetric constant marginal cost functions of both the consumerfriendly firm and the absolute profit-maximizing firm. In one of our future studies, we will consider the welfare implications under the assumption that the two firms have asymmetric cost functions and/or increasing marginal cost functions. Furthermore, as one of the next plausible steps, we must conduct a similar analysis to that provided in this paper by considering the separation 
between ownership and management in each firm. In particular, in a duopoly with a consumer-friendly firm and with separation between ownership and management, which was investigated in Goering [13] and Kopel and Brand [9], the manager maximizes the weighted sum of absolute profit $(\pi)$ and weighted consumer surplus $(\theta C S)$ with respect to the strategic delegation parameter $\gamma$, which is equal to $(1-\gamma) \pi+(\gamma+\theta) C S^{9}$. Future research must deal with the above problems.

\section{REFERENCES}

[1] P. Auger, P. Burke, T. M. Devinney and J. J. Louviere, "What Will Consumers Pay for Social Product Features?" Journal of Business Ethics, Vol. 42, No. 3, 2003, pp. 281304. http://dx.doi.org/10.1023/A:1022212816261

[2] R. Trudel and J. Cotte, "Does It Pay to Be Good?" Sloan Management Review, Vol. 50, No. 2, 2009, pp. 61-68.

[3] A. McWilliams, D. Siegel and P. M. Wright, "Guest Editors Introduction-Corporate Social Responsibility: Strategic Implications," Journal of Management Studies, Vol. 43, No. 1, 2006, pp. 1-18.

[4] S. Brammer and A. Millington, "Does It Pay to Be Different? An Analysis of the Relationship between Corporate Social and Financial Performance," Strategic Management Journal, Vol. 29, No. 12, 2008, pp. 1325-1343. http://dx.doi.org/10.1002/smj.714

[5] A. B. Carroll and K. M. Shabana, "The Business Case for Corporate Social Responsibility: A Review of Concepts, Research and Practice," International Journal of Management Reviews, Vol. 12, No. 1, 2010, pp. 85-105. http://dx.doi.org/10.1111/j.1468-2370.2009.00275.x

[6] P. C. Godfrey, C. B. Merrill and J. M. Hansen, "The Relationship between Corporate Social Responsibility and Shareholder Value: An Empirical Test of the Risk Management Hypothesis," Strategic Management Journal, Vol. 30, No. 4, 2009, pp. 425-445. http://dx.doi.org/10.1002/smj. 750

[7] A. J. Hillman and G. D. Keim, "Shareholder Value, Stakeholder Management, and Social Issues: What's the Bottom Line?" Strategic Management Journal, Vol. 22, No. 2, 2001, pp. 125-139. http://dx.doi.org/10.1002/1097-0266(200101)22:2<125:: AID-SMJ150>3.0.CO;2-H

[8] J. Surroca, J. A. Tribo and S. Waddock, "Corporate Responsibility and Financial Performance: The Role of Intangible Resources," Strategic Management Journal, Vol. 31, No. 5, 2010, pp. 463-490.

[9] M. Kopel and B. Brand, "Socially Responsible Firms and Endogenous Choice of Strategic Incentives," Economic Modelling, Vol. 29, No. 3, 2012, pp. 982-989. http://dx.doi.org/10.1016/j.econmod.2012.02.008

[10] T. Besley and M. Ghatak, "Retailing Public Goods: The Economics of Corporate Social Responsibility," Journal of Public Economics, Vol. 91, No. 9, 2010, pp. 16451663. http://dx.doi.org/10.1016/j.jpubeco.2007.07.006

[11] L. Lambertini and A. Tampieri, "Corporate Social Responsibility in a Mixed Oligopoly," University of Bologna, Bologna, 2010.

[12] N. Singh and X. Vives, "Price and Quantity Competition in a Differentiated Duopoly," RAND Journal of Economics, Vol. 15, No. 4, 1984, pp. 546-554. http://dx.doi.org/10.2307/2555525

[13] G. E. Goering, "The Strategic Use of Managerial Incentives in a Non-Profit Firm Mixed Duopoly," Managerial and Decision Economics, Vol. 28, No. 2, 2007, pp. 83-91. http://dx.doi.org/10.1002/mde.1307

[14] G. E. Goering, "Welfare Impacts of a Non-Profit Firm in Mixed Commercial Markets," Economic Systems, Vol. 32, No. 2, 2008, pp. 326-334. http://dx.doi.org/10.1016/i.ecosys.2008.06.002

[15] G. E. Goering, "Socially Concerned Firms and the Provision of Durable Goods," Economic Modelling, Vol. 25, No. 3, 2008, pp. 575-583. http://dx.doi.org/10.1016/j.econmod.2007.10.001

[16] C. Fershtman and K. Judd, "Equilibrium Incentives in Oligopoly," American Economic Review, Vol. 77, No. 5, 1987, pp. $927-940$.

[17] S. D. Sklivas, "The Strategic Choice of Management Incentives," RAND Journal of Economics, Vol. 18, No. 3, 1987, pp. 452-458. http://dx.doi.org/10.2307/2555609

[18] J. Vickers, "Delegation and the Theory of the Firm," Economic Journal, Vol. 95, Supplement: Conference Papers, 1985, pp. 138-147.

\footnotetext{
${ }^{9}$ In their model, the owner of the consumer-friendly firm maximizes the weighted sum of its absolute profit and consumer surplus $(\pi+\theta C S)$, which is its payoff with respect to $\gamma$, similar to the basic strategic managerial delegation model à la Fershtman and Judd [16], Sklivas [17], and Vickers [18]. In addition, parameter $\theta$ denotes the extent of the importance of consumer surplus to the consumer-friendly firm, which is similar to this paper.
} 


\section{Appendix}

The concrete value of the difference between $W^{q q}$ and $W^{p p}$

Comparing the equilibrium social welfare between the quantity competition and the price competition, we obtain the following result:

$$
W^{q q}-W^{p p}=\frac{a^{2} b\left[2 b^{3}(1-\theta)^{2}+4(1-\theta) \theta-b\left(8-8 \theta+3 \theta^{2}\right)+b^{2}\left(4-4 \theta+3 \theta^{2}\right)\right]}{2(1+b)\left[4-b^{2}(1-\theta)-2 \theta\right]^{2}} .
$$

